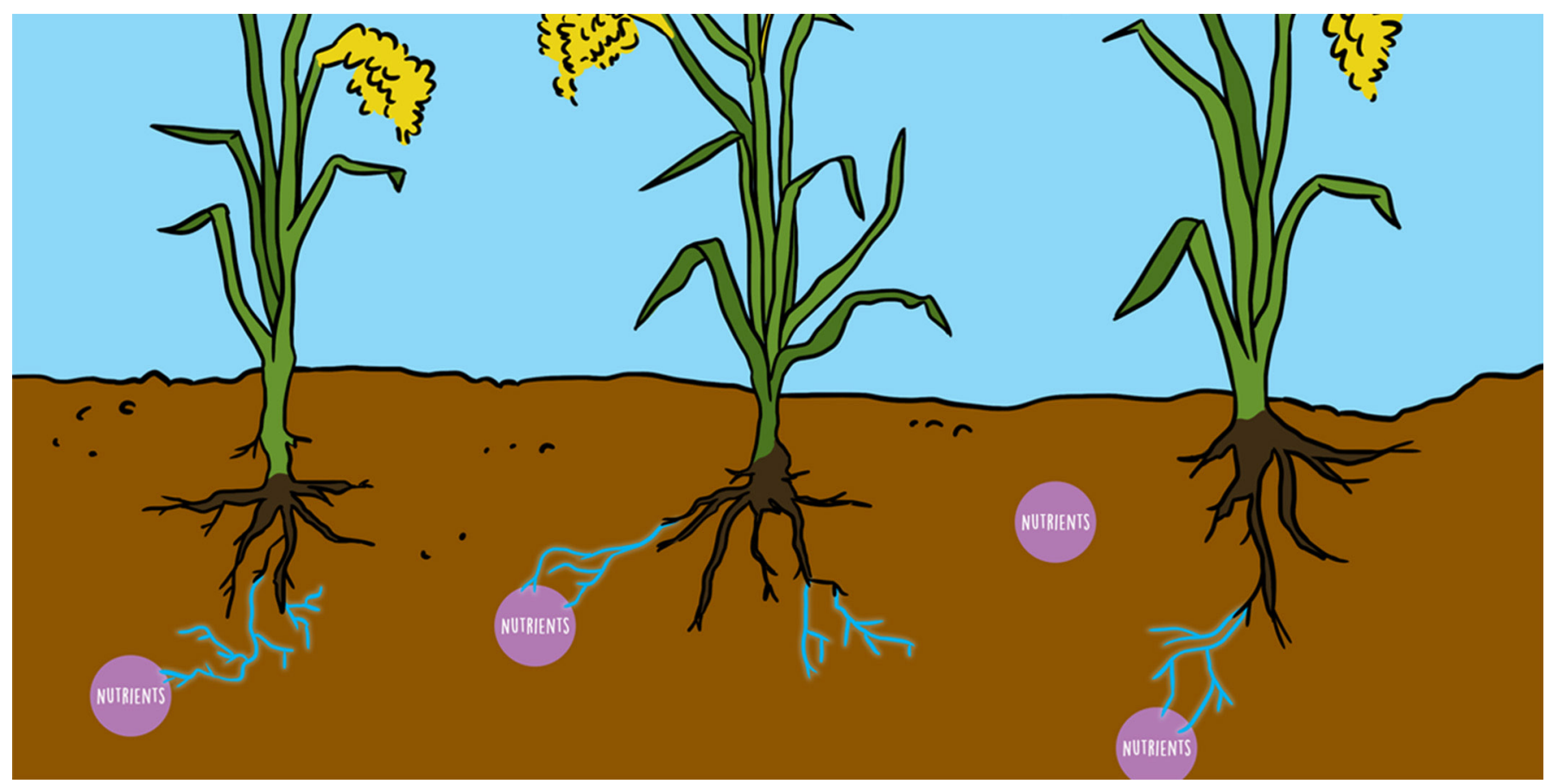

\title{
UNDERGROUND FUNGI: FRIENDS AND ENEMIES OF RICE PLANTS
}

\section{Lina Bernaola ${ }^{*}$, James Stiernberg ${ }^{2}$ and Michael J. Stout ${ }^{1}$}

${ }^{1}$ Department of Entomology, Louisiana State University Agricultural Center, Baton Rouge, LA, United States

2 Department of Petroleum Engineering, Louisiana State University, Baton Rouge, LA, United States

\section{YOUNG REVIEWERS:}

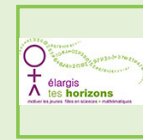

EXPANDING YOUR HORIZONS

AGES: $12-15$
Humans have been growing rice for thousands of years, but we have not been doing it alone this whole time. With over 7.6 billion mouths to feed on our hungry planet, would not you want to get as much help as possible when growing food? We can easily see caterpillars, such as the fall armyworm, eating rice leaves above ground, but there are also insects, like immature rice water weevils, feeding on the roots underground. So, who is the mysterious helper in these scenarios? Fungi! Rice plants are able to provide nutrition for themselves, but when they team up with arbuscular mycorrhizal fungi (AMF), they can more efficiently obtain the building blocks needed to grow. From our results, we think that maybe AMF can help plants repair themselves following pest damage. This could lead to a reduction in pesticides used and, more importantly, more food for everyone to eat. 


\section{INTRODUCTION}

Earth's population has exploded in the last 200 years, and it is estimated that over 7.6 billion people currently live on Earth today! With that many mouths to feed, how do farmers keep up? There are common types of food, like grains, that are cultivated in large amounts by people all over the world. Rice, for example, has been grown by human civilizations for over 4,000 years and is grown on every continent except Antarctica! Growing rice has been so popular because it can thrive in so many different conditions. However, rice plants face some major challenges, such as insect pests that feed on rice plants while they grow. One of the ways that rice farmers reduce the threat of insect pests is by using insecticides. While insecticides have been effective in controlling some plant-eating pests, they also carry the risk of endangering human health. One way humans have learned to help rice and other crops deal with plant-eating pests or other threats is by making friends with certain fungi. There are some fungi that live in the soil that can protect different crop plants [1], similar to the way vitamins and medicines protect the human body against colds and infections. Beneficial organisms like these fungi can potentially reduce our reliance on insecticides.

\section{THE RHIZOSPHERE: A WHOLE WORLD RIGHT BENEATH YOUR FEET}

Plants are exposed to attackers above ground, and they also face difficulties below ground. The zone surrounding the roots of a plant is its own little community called the rhizosphere, and it is not an empty neighborhood! The soil around roots is full of microorganisms. Of these microorganisms, there are some that establish give-and-take relationships with the roots of plants. One such group of soilborne organisms is called arbuscular mycorrhizal fungi (AMF), which we abbreviate as AMF. How could such a community in the rhizosphere be of help to its plant host?

Arbuscular mycorrhizal fungi ("Arr-bus-cue-ler My-core-rise-uh

Fun-guy") are organisms that live in the soil and form long-term, strong relationships with the roots of host plants in order to exchange resources.

Well, you are free to move about to grab a nutritious snack or go to the doctor for prescriptions when you feel sick. Plants cannot walk, so they depend on their roots to search for water and nutrients. Roots are limited in length, of course, so plants look to other sources for help, including AMF. AMF are fungi (related to mushrooms) that are similar in appearance to roots and they enable the plant's roots to reach more nutrients required for growth (Figure 1). The structure of AMF is much finer than plant roots though, so the fungi are able to absorb minerals more efficiently than the plant [2]. Because of their structure, they can deliver higher doses of mineral building blocks to plants, just like chewable vitamins can give your body the building blocks it needs 
Figure 1

Symbiosis between AMF and a few cells in the outer layer of a plant's root tissue. An AMF spore cell, shown as a brown circle, has extended hyphae through the rhizosphere and into the plant's root cells. The tree-shaped structure of the AMF, called arbuscules, helps it interact with the plant cells, and the round vesicles in various cells allow the AMF to accumulate the nutrients received from the host plant.

\section{SYMBIOSIS ("SIM-} BEE-OH-SIS")

A partnership between two organisms. The association usually helps both partners thrive in their environment.

\section{SPORE ("SPOUR")}

A single reproductive cell having the ability to generate a new individual fungus without needing to combine with another fungus or spore.

\section{FUNGUS}

Fungi form a group of organisms, both helpful and harmful, that feed on other organic matter; typical examples include mold and mushrooms.

\section{BIOTROPHIC ("BY-} OH-TROFF-ICK")

Describes the longterm feeding arrangement between a fungus and the cells of a host plant, in which the cells of the host plant are not harmed.

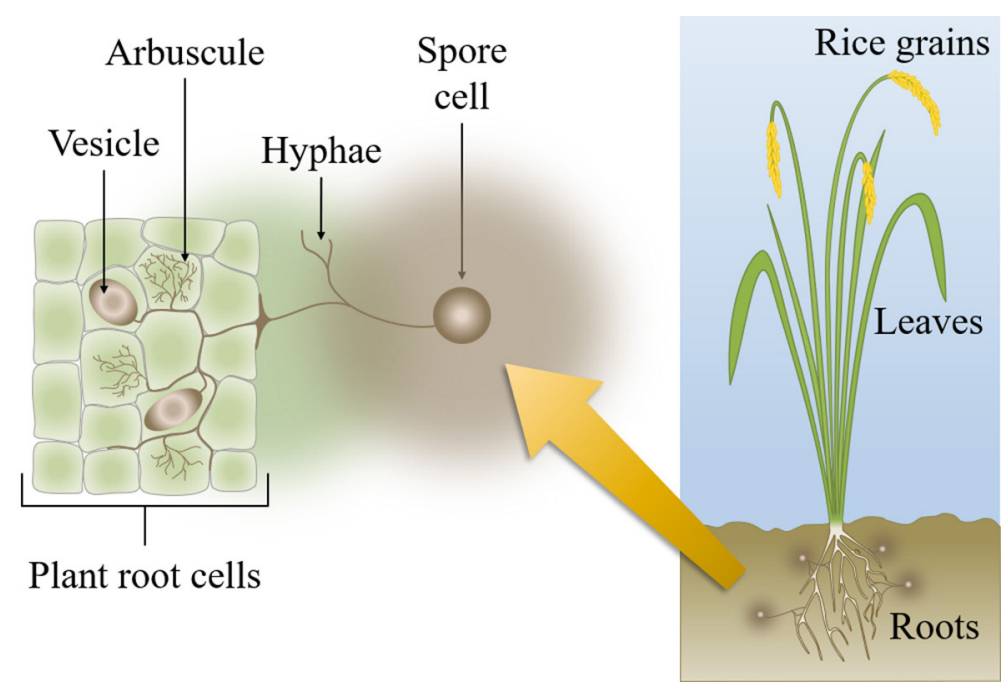

Figure 1

quicker than food can alone. In particular, AMF absorb the nutrients phosphorous and nitrogen from the soil and transfer these nutrients to the plant. In exchange for this help, the plant also provides the fungi with essential nutrients. This relationship is called a symbiosis, because it is a partnership in which both sides cooperate closely with one another and benefit from one another.

The main parts of a plant are the leaves, stem, and roots. AMF begin as small, individual cells called spores and have hyphae, which are very thin, branchlike structures that connect different areas of the fungi together. AMF also have vesicles, which are round structures that store the nutrients the fungus gathers from the soil, and arbuscules, which are tree-shaped structures that allow the exchange of nutrients with the roots of the host plant [3]. These three structures, shown in Figure 1, help us to understands why the fungi have this name: the name comes from the form of the fungus and the relationship that it creates with the plant.

AMF are called biotrophic because of this symbiosis with plants. Biotrophs must have another host plant (such as corn, rice, cotton, wheat, lentils, etc.) for a long-term feeding partner, in order to exist! So, how do AMF and plant roots find each other? Communication between plant roots and AMF involves a sequence of events, but ultimately concludes when the fungi penetrate the root to begin colonization of the root cells.

\section{RICE AND ITS ENEMIES}

Besides the exchange of nutrients with plants, another role fungi have is to help protect the plants against different stresses, such as 
herbivorous (plant-eating) insects. Did you know, during the rice season, that different insects attack the rice plant at different times? Rice plants can come under attack as soon as their seeds are planted until the time they are harvested at the end of their life cycle. In the United States, this life cycle usually begins with the planting of seeds into dry soil. At some point, usually within a month of planting, the field is flooded. This is the best growing condition for most types of rice, and it helps defeat some weeds that would otherwise crowd out the rice.

Once the plant is about 1 month old, and the flood has been wellestablished, the rice plant is exposed to more threats. There are several herbivorous insects that feed on rice in the United States, but we will only focus on two. One tiny insect, called the rice water weevil, shows up in the rice fields at an early stage of the plant's life. After male and female weevils mate, the females lay eggs, which then later hatch into larvae. The larval weevils dig below the surface to feed on the root system of the rice plant. They will remain there, eating away at the rice plant's roots while the weevils mature (see Figure 2). If there are many weevils, then they can remove enough of the roots that there will not be enough of a root system to support the growth of the rice plant (see Figure 3). When rice water weevil infestations become severe enough, the amount of rice produced per plant will be much less than it could be!

Also, during the rice's life, another insect called the fall armyworm shows up. It does not burrow underground but prefers to snack on the leaves of the plants above ground. These insects are the young versions of a common type of moth. They can destroy an entire field by eating the leaves of the plants.

Figure 2

Common pests, such as rice water weevil and fall armyworm, attack rice throughout the plant's life cycle. The weevil larvae target the underground roots, while the adult weevils and fall armyworms chew on the leaves of the plant above ground.

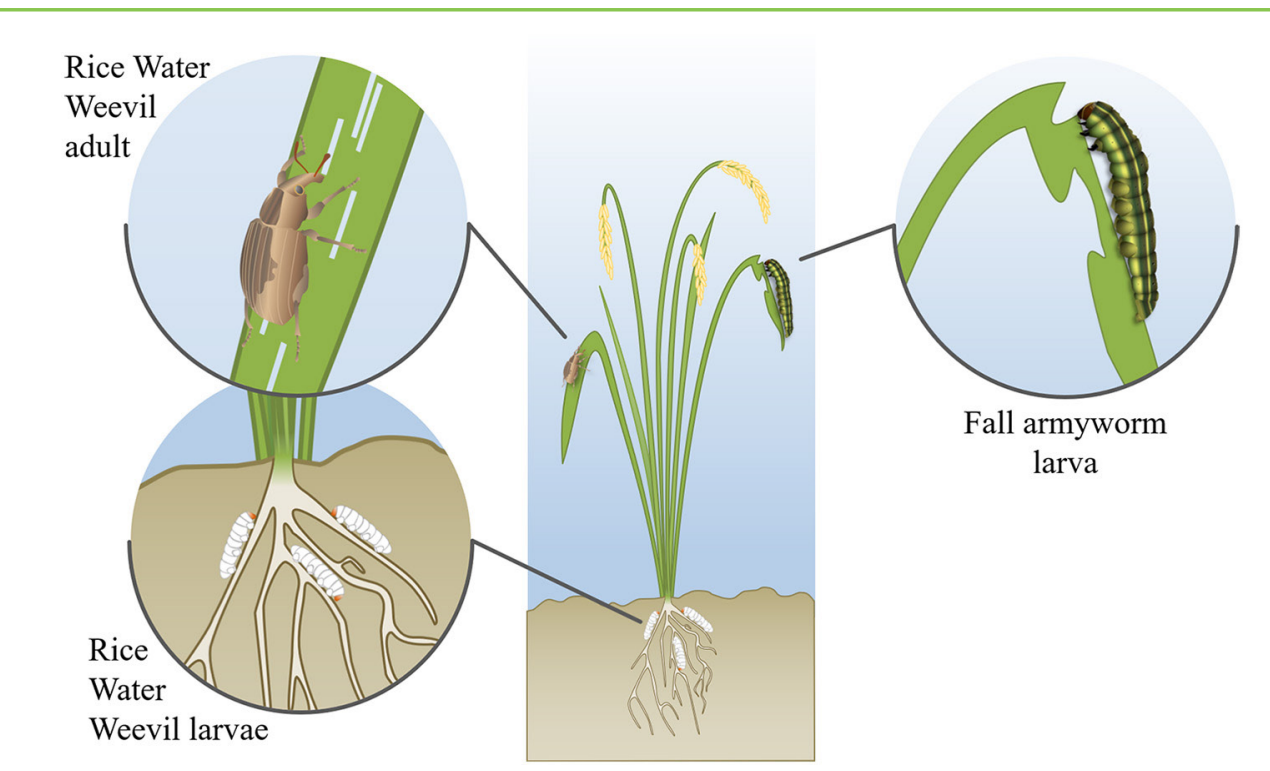

Figure 2 


\section{Figure 3}

Rice water weevil root damage to rice plants. The rice plants on left have short roots due to damage from rice water weevil larvae feeding on them, and the plants on right have longer, undamaged roots (photo: Lina Bernaola)

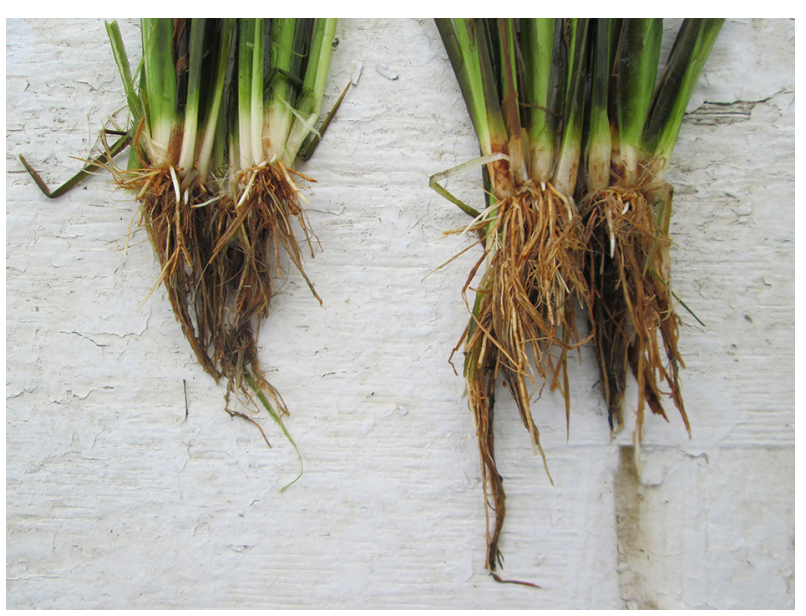

Figure 3

How can plants fight back? Arbuscular mycorrhizal fungi help the plant survive the stress of herbivore attacks. Luckily, AMF exist in many areas naturally, but farmers can also add AMF to the soil to give their rice crop its best chance of surviving. Scientists have seen that AMF encourage growth in some plants [4], but this may not always be the case with rice. AMF are a lot like medicine that we can take when we feel bad. However, just like the medicines we take, some work well for you while others do not. Sometimes, kids respond differently to the same treatment, and this is the case for plants in any type of symbiotic relationship.

\section{HOW DOES ALL THIS HELP MAKE MORE FOOD?}

If plants are protected from herbivorous pests, then they will be able to live long enough to produce food for more people. This could potentially reduce our reliance on insecticides and allow us to get more rice grains from the same size field. It is important to remember that insects are not the only things that cause damage to plants. The existence of other microorganisms in the rhizosphere can either help or hurt the growth of plants. This effect will depend on the particular rice crop and the type of microorganisms involved.

In addition to helping rice plants tolerate insect attacks, AMF can help plants to grow significantly more shoot (which is any part of the plant above ground, such as the stems, leaves, and flowers) than rice grown without AMF. If insects eat part of the plant, then AMF can potentially help the plant to regrow the lost plant material [5]. If the rice plants can regrow after being eaten, the pests will not reduce the size of the harvest as much. 


\section{TOO MUCH OF A GOOD THING?}

When AMF colonize the roots of a plant, they can sometimes lead to those bigger or taller plants just mentioned. Also, the symbiosis can help protect from the attack of herbivores by boosting the defenses plants use. It is similar to when you feel sick: you take medicine to help combat everything from colds to fevers. Your body does most of the hard work to remove whatever is making you sick, while the medicine provides some of the tools to make the job easier.

On the other hand, AMF can be bad for rice. They can weaken the plant by giving it too many nutrients. How could this possibly be bad? Well, if it gets too many nutrients, the rice plant will become larger and more irresistible to insects, which can see the difference between average and strong plants. For example, would not you rather dine on a large, red apple vs. a small, wrinkled one? Insects can be just as picky as we can!

\section{HOW DOES THIS RESEARCH MAKE A DIFFERENCE?}

Scientists are trying to understand the interactions between AMF and rice plants and the insects that feed on those plants so that we can better use AMF to increase the amount of rice that will help to feed our world's rapidly growing population. As you have seen, the interactions between fungi, plants, and insects is complex and depends on many things. However, using these natural farming methods, and avoiding the use of harmful insecticides, is part of our responsibility to keeping the planet healthy.

\section{AUTHOR CONTRIBUTIONS}

LB conceived the original idea. LB and JS wrote the first draft of the manuscript. LB developed the concept of figures and JS created the final images. MS edited the manuscript and all authors gave final approval for submission.

\section{ORIGINAL SOURCE ARTICLE}

Bernaola, L., Cosme, M., Schneider, R. W., and Stout, M. 2018. Belowground inoculation with arbuscular mycorrhizal fungi increases local and systemic susceptibility of rice plants to different pest organisms. Front. Plant Sci. 9:747. doi: 10.3389/fpls.2018.00747 


\section{REFERENCES}

1. Bennett, A. E., Alers-Garcia, J., and Bever, J. D. 2006. Three-way interactions among mutualistic mycorrhizal fungi, plants, and plant enemies: hypotheses and synthesis. Am. Nat. 167:141-52. doi: 10.1086/499379

2. Smith, S. E., and Smith, F. A. 2011. Roles of arbuscular mycorrhizas in plant nutrition and growth: new paradigms from cellular to ecosystem scales. Annu. Rev. Plant. Biol. 62:227-50. doi: 10.1146/annurev-arplant-042110-103846

3. Lanfranco, L., Fiorilli, V., and Gutjahr, C. 2018. Partner communication and role of nutrients in the arbuscular mycorrhizal symbiosis. New Phytol. 220:1031-46. doi: 10.1111/nph.15230

4. Bernaola, L., Cosme, M., Schneider, R. W., and Stout, M. 2018. Belowground inoculation with arbuscular mycorrhizal fungi increases local and systemic susceptibility of rice plants to different pest organisms. Front. Plant Sci. 9:747. doi: 10.3389/fpls.2018.00747

5. Barber, N. A., Adler, L. S., Theis, N., Hazzard, R. V., and Kiers, E. T. 2012. Herbivory reduces plant interactions with above- and belowground antagonists and mutualists. Ecology 93:1560-70. doi: 10.1890/11-1691.1

SUBMITTED: 11 July 2018; ACCEPTED: 07 March 2019;

PUBLISHED ONLINE: 29 March 2019.

EDITED BY: Robert T. Knight, University of California, Berkeley, United States

CITATION: Bernaola L, Stiernberg J and Stout MJ (2019) Underground Fungi: Friends and Enemies of Rice Plants. Front. Young Minds 7:50. doi: 10.3389/frym.2019.00050

CONFLICT OF INTEREST STATEMENT: The authors declare that the research was conducted in the absence of any commercial or financial relationships that could be construed as a potential conflict of interest.

COPYRIGHT @ 2019 Bernaola, Stiernberg and Stout. This is an open-access article distributed under the terms of the Creative Commons Attribution License (CC BY). The use, distribution or reproduction in other forums is permitted, provided the original author(s) and the copyright owner(s) are credited and that the original publication in this journal is cited, in accordance with accepted academic practice. No use, distribution or reproduction is permitted which does not comply with these terms.

\section{YOUNG REVIEWERS}

\section{EXPANDING YOUR HORIZONS, AGES: 12-15}

Expanding Your Horizons has been active in Geneva since 2009 with the goal of encouraging girls in the Geneva region to explore STEM careers, and to continue with mathematics and science in school. The non-profit association runs the bi-annual EYH conference, supported by local organizations. 


\section{AUTHORS}
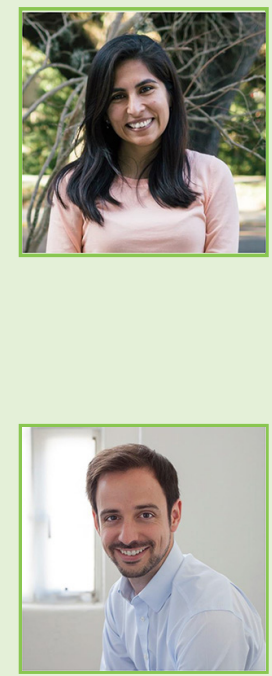

\section{LINA BERNAOLA}

Lina Bernaola is a Ph.D. candidate at Louisiana State University. Her research focus is on plant-microbe-insect interactions and she is currently working with rice. She has been fascinated by science her entire life, but her passion in the world of plants began when she joined the International Potato Center in Lima, Peru. She wants to use research to help develop more cost-effective management programs to fight insect pests. *lbernaola@agcenter.lsu.edu

\section{JAMES STIERNBERG}

Jim is a petroleum engineer with a M.S. from Louisiana State University; however, he considers himself more broadly as a scientist and problem solver. He used to take everything apart (usually breaking it in the process) when growing up. So, he chose a path in engineering, but always stayed curious about his environment. He enjoys rock climbing and hiking, which has allowed many strange insects to cross his path on weekend trips. He likes volunteering and finds it very rewarding to teach and show people new things or ways of thinking.

\section{MICHAEL STOUT}

Michael J. Stout is Professor and Head of Entomology at Louisiana State University. His research involves the interaction of rice with its major pests in Louisiana. He focuses on the mechanisms of rice resistance and tolerance to rice pests. His ultimate research goal is to develop cost-effective management programs for insect pests of rice. 